Early in the year Sir Walter Buller was taken seriously ill, and only a few months ago the writer was permitted, during what was hoped by the sufferer himself and his friends was a true convalescence, to see him, alas! for the last time. He was dictating from his couch the concluding pages of the final volume of his supplement "to get them off his mind." Unfortunately, a relapse supervening he was removed into the country to the home of Mrs. Madockss, the daughter to whom the supplement is "affectionately dedicated," " his constant companion during its preparation, and the contributor of some beautiful photographs of New Zealand scenery to its pages." It was hoped that the change would restore the patient sufficiently to enable him to take a long, curative sea voyage. These hopes have been disappointed, and this distinguished ornithologist's life closed at the comparatively early age of sixty-eight years, with the last page of the work on which he laboured so enthusiastically for half a century.

Sir Walter Buller published many natural history papers, especially in the Transactions of the New Zealand Institute, on other subjects besides his favourite birds. He was elected to the Fellowship of the Royal Society in 1879, and the honorary degree of D.Sc. was conferred by Cambridge in 1903 in recognition of his scientific work.

Besides being a busy City man, Sir Walter held many public offices. He acted as Commissioner for New Zealand at the Colonial and Indian Exhibition of I866, on the executive council of the Paris Exhibition in 1889 , and for five years on the governing body of the Imperial Institute. He was created K.C.M.G. in 1886 . A large donor to many museums at home and abroad, he received decorations from many foreign States in recognition of his generosity.

\section{THE YORK MEETING OF THE BRITISH ASSOCIATION.} $T_{\text {ation may be described as a very successful one. }}^{\mathrm{HE} \text { senty-sixth meeting of the }}$ The Association was founded in York in 183r. It visited York again in 1846 , and also in 1880 . On the present occasion the citizens, who are proud of the connection of their ancient city with the association, welcomed the members with the greatest cordiality and hospitality. The meeting was favoured with exceptionally good weather, and as the programme left little to be desired, those who visited York on this occasion carried away with them very pleasant memories.

The old city looked its best. Socially, the meeting was everything that guests and hosts alike could have wished. The attendance at the meeting was 1959; that at the meeting in $183 \mathrm{r}$ was 359 .

We gave in our last number Prof. E. Ray Lankester's presidential address, as well as the names of the distinguished foreign men of science who attended the meeting, a number of whom received honorary degrees at Leeds University on Saturday, August 4.

The exhibition building proved very satisfactory; it would, in fact, be difficult to find a building better adapted for such a rendezvous. The reception room was adequate in all respects, and the great hall, handsomely decorated, had the appearance of a new building. Shrubs and bamboos with a well-judged sprinkling of Lilium speciosum relieved the eye, and hanging baskets at intervals depended from the galleries.

The best thanks of citizens and visitors alike are due to the local secretaries, Mr. Charles E. Elmhirst and Mr. Henry Craven (Town Clerk of York), as well as to the acting secretary, Mr. Fred. Arey, whose experience in such matters proved invaluable.

The two evening discourses in the great hall of the exhibition buildings were delivered by Dr. Tempest Anderson and Dr. A. D. Waller, F.R.S., the subject of the former being "Volcanoes," while that of the latter was "The Electrical Signs of Life, and their Abolition by Chloroform." Large and attentive audiences packed the building, and showed every sign of interest in the subjects laid before them. The photographs of the late eruption of Vesuvius and its results were specially attractive.

The various sections were attended by. large audiences, and offered so many subjects of interest that it is difficult to say which proved the most generally attractive. In many of the sections the presidents, in their opening addresses, dealt with the advance of science during the period of twentyfive years which has elapsed since the last meeting of the society in York.

At a meeting of the General Committee on August I, the report of the Council was read. Action has been taken by the Council in accordance with the recommendations made in the following resolutions from Sections $\mathrm{A}$ and $\mathrm{H}$ :-

From Section A.-(I) The Committee, being of opinion that the completion of the Geodetic Arc from the South to the North of Africa is of the utmost scientific importance, and that the establishment of a Topographical Survey is of an importance that is at once scientific and economic, respectfully request the Council to make representations in such form as they think fit to urge upon the British South Africa Company the desirability of taking advantage of the present favourable opportunity for joining up the triangulation north and south of the Zambesi, and also to urge upon the Governments of the South African Colonies the immense practical and economic importance of commencing the topographical survey.

(2) The Committee desire to draw attention to the importance of a Magnetic Survey of South Africa, and respectfully request the Council of the Association to approach the Cape Government with a view to urging on them the great advantages which would accrue to Science and to South Africa if the Government would further support and assist the Survey which has already been partly made by Prof. Beattie and Prof. Morrison, and for the continuation of which a Special Committee of the Association is being appointed to conperate with these gentlemen.

A grant of $300 l$. from the Special South Africa Fund has been made by the Council to Sir David Gill, for the purpose of completing. the connection between the Rhodesian and Transvaal triangulations along the thirtieth meridian of East longitude.

From Section H.-(I) That it is desirable that the Governments of the South African Colonies be urged to take all necessary steps to collect, record, and preserve the knowledge and observations of men, such as missionaries, administrators, and others, who were living in intimate relations with the native tribes before the advance of civilisation began to obscure and even obliterate all true traditions, customs, and habits of the South African peoples; such steps to be taken without delay, especially in view of the old age and growing infirmities of most of the men referred to, and of the danger that with their deaths the knowledge which, if carefully recorded and preserved, would form a most valuable contribution towards the history of the aboriginal population, would be irrecoverably lost; and that the Council be recommended to communicate with the South African Association and suggest the appointment of a committee to deal with the matter. No. 1919. VOL. 74] 
(2) That, owing to the use by different writers and Government authorities of various names for the same groups of South African natives, much confusion and difficulty have arisen in anthropological and historical literature; that it is consequently desirable that Government authorities and others should confer as to the proper nomenclature of such groups (clans, tribes, and nations), with a view to ascertaining their inter-relationships, and to suggesting the most appropriate name for each group, and the best method of spelling that name phonetically; and that the Council be recommended to communicate with the South African Association and take such other steps as may conduce to this object.

(3) That the Committee are of opinion that it would conduce to the greater efficiency of officers who have to administer native affairs, and contribute to the advancement of anthropological science, as well as prove of considerable advantage to the well-being of the natives themselves, if opportunity could be given to such officers before or after their appointment to study comparative ethnologv for at least two terms in one of the Universities of the United Kingdom which presents facilities for the study; and that in the case of junior officers already on active service such a course of study would facilitate their comprehension of native institutions and ideas, and help to render their services more efficient; and the Committee recommends the Council to take steps for the purpose of bringing this matter before the proper authorities.

At the meeting of the General Committee on August 3, the date of the opening meeting at Leicester next year was fixed for July 3o. Sir David Gill, K.C.B., F.R.S., will be the president. The meeting in 1908 will be in Dublin, and that of 1909 at Winnipeg, Canada.

Subjoined is a synopsis of grants of money appropriated to scientific purposes by the General Committee :-

Section A.-Mathematical, and Physical Science.

Electrical Standards

$\begin{array}{lllllll}\cdots & \cdots & \cdots & \ldots & 50 & 0 & 0\end{array}$ $\begin{array}{lllllll}\text { Seismological Observations } & \ldots & \ldots & \ldots & 40 & 0 & 0\end{array}$ Magnetic Survey of South Africa..

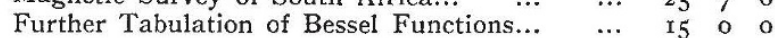

Section B.-Chemistry.

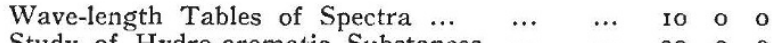
Study of Hydro-aromatic Substances $\quad \ldots \quad$ …

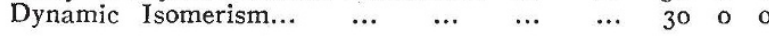

\section{Séction C.-Geology.}

Life Zones in British Carboniferous Rocks Erratic Blocks Fossiliferous Drift Deposits $\ldots \begin{array}{llllll}\ldots & \ldots & \ldots & 25 & 19 & 0\end{array}$ Fauna and Flora of British Trias ... ... ro 0 ro 0

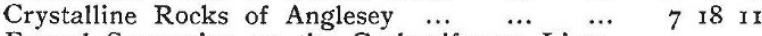

Faunal Succession on the Carboniferous Limestone of S.W. England ... $\quad \ldots \quad$...

Correlation and Age of South African Strata, \&c.

Investigation of the $\dddot{\text { Speeton }} \cdots$ Beds at Knapton...

$$
\text { Section D.-Zoology. }
$$

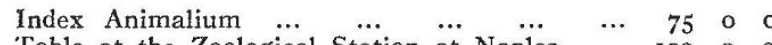

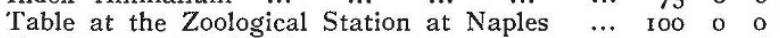
Development of the Frog ... $\ldots . . . . \quad \ldots \quad 5$ I4 6 Respiratory Phenomena and Colour Changes in

Experiments on the $\ddot{\text { Development of the Sexual }}$ Cells

\section{Section E.-Geography.}

Oscillations of the Land Level in the Mediterranean Basin

Rainfall and Lake and River Discharge $\quad \ldots$ NO. I 19 , VOL. 74]
II 20

500
Section F.-Economic Science and Statistics.

International Trade Statistics $\ldots$... United
Gold Coinage in Circulation in the Unite Es.d. Kingdom

\section{Section H.-Anthropology.}

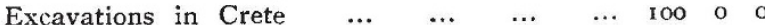

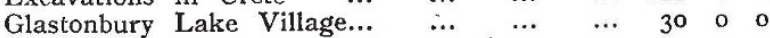
Excavations on Roman Sites in Britain... $\quad \ldots$. I5 0 ... Anthropometric Investigations $\quad \ldots \quad$... $\begin{array}{lllllllll}\text { Age of Stone Circles } & \ldots & \ldots & \ldots & \ldots & 3 & 0 & 0\end{array}$ Anthropological Photographs $\quad \ldots \quad$...

Section I.--Physiology.

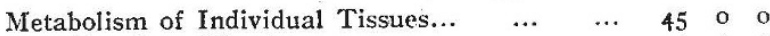

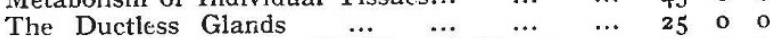

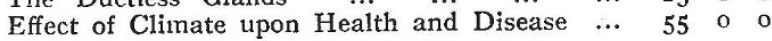

$$
\text { Section K.-Botany. }
$$

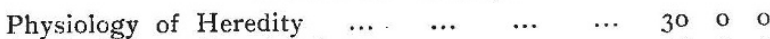

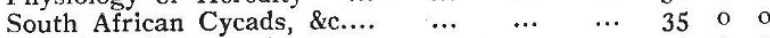
$\begin{array}{llllllrll}\text { Botanical Photographs } & \ldots & \ldots & \ldots & \ldots & 5 & 0 & 0\end{array}$ $\begin{array}{llllllll}\text { Structure of Fossil Plants } & \ldots & \ldots & \ldots & \ldots & 5 & 0 & 0\end{array}$ $\begin{array}{llllllll}\text { Peat Moss Deposits ... } & \ldots & \ldots & \ldots & \ldots & 7 & 5 & 7\end{array}$ $\begin{array}{lllllllll}\text { Marsh Vegetation } & \ldots & \ldots & \ldots & \ldots & \ldots & \text { 15 } & 0 & 0\end{array}$

\section{Section L.-Educational Science.}

Studies suitable for Elementary Schools... $\quad \ldots \quad$ Io 0 o Conditions of Health in Schools ... $\quad \ldots \quad$...

Corresponding Societies Committee.

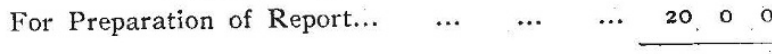

Total $\ldots \quad \ldots \quad \ldots$ 106r $12 \quad 4$

\section{SECTION A.}

MATHEMATICS AND PHIYSICS.

Opening Address by Principal E. H. Griffiths, Sc.D., F.R.S., President of the Section.

My predecessors in this Chair have in general been able to make communications to the Section conveying the results of investigations of their own, or enunciating some principle which would throw a fresh light on the discoveries of others. Mine is a far less happy lot. During the past four years and a half $I$ have been engaged in administrative duties of such a nature that no time has been available for personal scientific work, and little energy even for the study of the work of others. In these circumstances it might have seemed more fitting if $I$ had refused the honour which the Council of the British Association conferred upon me by the request that I would undertake the arduous duties which fall to the lot of the President of Section A. Nevertheless, after much hesitation, I decided to accept the invitation, in the hope that as a lookeron at the struggle of others, and with the experience of an old participator in the fray, I might be able to communicate some impressions which had possibly escaped I5 00 the notice of those whose attention was necessarily more directed to some special branch of inquiry.

10 0 a I trust that these words of apology may to some extent Io o o explain the nature of what must appear a fragmentary discourse.

In the interval which has elapsed since the last meeting of the Association we have lost many men whose names were household words within the walls of the physical laboratory. It is here only possible briefly to refer to the labours of a few of those distinguished seekers after natural knowledge.

The work of Dr. Sprengel has been by no means an unimportant factor in the advance of our knowledge of radiant energy, X-rays, \&c., if only on account of the perfection of the apparatus for obtaining high vacua which will ever be associated with his name. The practical effect of his discoveries was considerable, for the business of electric
lighting is undoubtedly greatly indebted to his labours.

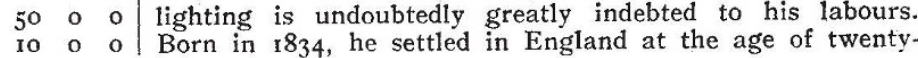


five. He was elected a Fellow of the Royal Society in 1878 , and resided in this country during the remaining years of his life.

The death of Charles Jasper Joly, F.R.S., at the early age of forty-one; robbed mathematics and astronomy of one of their most devoted disciples. His "Manual of Quaternions" is well known, and those acquainted with his astronomical work are confident that, had his life been spared, he would, as Astronomer Royal of Ireland, have added lustre to an office held by many distinguished predecessors.

Samuel Pierpont Langley was born in 1834 . In 1866 he became Director of the Alleghany Observatory at Pittsburg. His first work was the institution of a uniform system of time from the Atlantic seaboard to the Great Lakes. This, the first successful attempt to introduce uniformity of time over a large area, was subsequently widely imitated. In 1880 he invented the bolometer, and thus opened out a large new field of investigation into the invisible rays of long wave-length proceeding from heated bodies. He analysed in minute detail the lunar heat spectrum, and, more recently, he conducted an inquiry into the nature of the radiations emitted by the glow-worm. In $\mathrm{I} 88 \mathrm{I}$ he conducted his researches into the solar heat of the earth's atmosphere. In 1887 he became Secretary to the Smithsonian Institution. The result of twenty years' labour is to be found in the accurate determination, by temperature alone, of more than seven hundred lines in the invisible red spectrum, lines which are fixed with an average probable error of about one second of arc. In $189 \mathrm{I}$ he published his experiments in aërodynamics, in 1893 "The Internal Work of the Wind," and in 1896 he demonstrated by actual experiment that a body nearly a thousand times heavier than air can be driven through and sustained by it. His published works show great literary charm. He especially excelled in the presentation of abstruse subjects in simple and non-technical language. This is, perhaps, hardly the occasion to refer to his social qualities. Those who had the privilege of his acquaintance, however, can best testify to his quickness of insight, his intense sympathy, especially with the young, and the impression of capability which he produced upon all with whom he came in contact.

The tragic death of Prof. Curie was felt as a calamity, not only by those closely interested in the march of scientific discovery, but also by those who had but a superficial knowledge of his work. A teacher for more than twenty years, he was nevertheless enabled by his enthusiasm and energy to perform those researches which will ever be connected with his name and that of his wife. So entirely has public attention been attracted to their joint work on the separation of the compounds of radium and their properties that we are apt to overlook other great services he rendered to science. His paper on "The Effect of Temperature on the Magnetic Properties of Bodies" led to the discovery of the law that for feebly magnetic substances the coefficient of magnetism varies inversely as the absolute temperature. $\mathrm{He}$ also pointed out that the magnetisation of diamagnetic substances appeared to be independent of the temperature and physical state, indicating diamagnetism as an atomic property.

It is pleasing to reflect that the importance of his discoveries received immediate recognition. It was but three years before his death that he announced to the French Academy the discovery of the new element, and in the same vear he and Mme. Curie received the Davy Medal of the Royal Society and the Nobel Prize; and in July of last year he was elected to the French Académie des Sciences. $\mathrm{He}$ was one of the most modest and retiring of men, and this honour came to him unsought; his name will ever be remembered as one of the most notable of that brilliant band of workers who have within recent years so greatly extended the domain of physics by the discovery of radioactivity.

A quarter of a century has passed since this Section, meeting in this city of York, had the privilege of listening to a Presidential address by the pioneer of natural knowledge whom we now know as Lord Kelvin, and it may possibly be a not unprofitable task to review briefly

No. I 9 I 9, VOL. 74] a few of the advances which must render the interval a memorable one in the annals of science.

Lord Kelvin summarised the stores of energy from which mechanical effects can be drawn by man as follows :-

(I) The food of animals.

(2) Natural heat.

(3) Solid matter found in elevated positions.

(4) The natural motions of water and air.

(5) Natural combustibles.

(6) Artificial combustibles.

The twenty-five years which have since elapsed have not made it possible to extend this list. It is true that within the last few years the discoveries connected with radioactivity have enormously increased our estimate of the stores of energy surrounding us, but so far these additional stores cannot be regarded by us as stores from which " mechanical effects may be drawn by man." It is possible that in the ingenious radium clock which we owe to $\mathrm{Mr}$. Strutt we have a source of mechanical energy unsuspected in $188 \mathrm{r}$, but, at all events, regarded from a commercial standpoint, it can hardly be considered as "available by man." Nevertheless, there is a sense in which it may be said that we are profiting by atomic energy, for we are no longer bound to limit our estimate of the energy due to the radiant heat of the sun and the internal heat of the earth by previously known dynamical considerations, and, in consequence, our opinions with regard to the limit of the ages which the physicist could allot to the evolutionist have undergone profound modification.

I here wish to draw attention to some of the conclusions to which we are led by the work of Mr. Strutt.

Assuming the earth to be in thermal equilibrium, then, even if the whole of this interior heat be due to radium alone, the mean quantity per cubic centimetre cannot much exceed $1.75 \times 10^{-13}$ gram. The conclusions of Rutherford, based on somewhat different values for the constants involved, give an equivalent of $1.52 \times 10^{-13}$. Now Strutt has found that the poorest igneous rock examined by him, namely, Greenland basalt, contains more than ten times this quantity, and an average rock fifty or sixty times the amount. The assumption that the earth is cooling only aggravates the difficulty, and facts appear to tell against the theory that it is getting hotter. Also, we must take into consideration the heat due to the existence of uranium, thorium, \&c.

We appear, therefore, to be driven to one of two assumptions : either $(a)$ that the rate of heat production by radium diminishes as we approach the centre of the earth; or $(b)$ that the interior of the earth differs markedly in constitution from the exterior crust.

It is true that Mr. Makower has shown that there is a slight change of activity in one of the radium products about the temperature of $1200^{\circ} \mathrm{C}$., and it is very desirable that this inquiry should be pushed to much higher limits. At the same time, it appears evident that but a very slight change in activity takes place at temperatures below $1500^{\circ} \mathrm{C}$.

Now Mr. Strutt has shown, arguing from known data, that the maximum temperature at the bottom of a crust of about forty-five miles in thickness, must be in the neighbourhood of $1530^{\circ} \mathrm{C}$., although some amount of uncertainty is necessarily induced by our want of knowledge of the conductivity of rock at high temperatures. Anyhow, it is probable that at the depth indicated the temperature does not exceed the melting-point of platinum. Such a crust would contain about one-thirtieth of the earth's volume, and if throughout it the radium heat energy were of the average of that exhibited by many samples examined by Strutt, the temperature of the earth could be maintained until our stores of uranium suffered sensible depletion. Such an assumption would lead to the conclusion that the whole of the central portion of the earth consists of nonradio-active substances at an approximate uniform temperature somewhat below the melting-point of platinum. A brief summary of the evidence previously at our disposal may not be out of place.

In the first edition (1867) of Thomson and Tait's " Natural Philosophy" we find the tidal evidence summarised as follows: "It seems certain, therefore, that the 
tidal effective rigidity of the earth must be greater than that of glass."

In the $188_{3}$ edition of the same work a discussion of the question by Prof. George Darwin is given. He states: "On the whole we may fairly conclude, whilst there is some evidence of a tidal yielding of the earth's mass, that yielding is certainly small, and that the effective rigidity is at least as great as steel.'

In a later paper (Proc. Roy. Soc., 1885) Darwin pointed out that this conclusion was based on the assumption that oceanic tides would have their equilibrium value, and that the validity of this assumption was open to doubt. Nevertheless, the evidence clearly indicated a high degree of effective rigidity.

Hough (Phil. Trans., A, 1895, 1896) discussed the variation of latitude, and, after correcting a small mistake of Newcomb's (who was the first to suggest the explanation), found the prolongation of the Eulerian Nutation from 305 to 430 days as indicating an effective rigidity of the earth about equal to that of steel. Wiechert (Trans. Roy. Soc. Göttingen, 197), of Göttingen, found that the mean density, ellipticity, and precessional constant were consisterit with the hypothesis of homogeneous core with lighter surface layer.

Mr. R. D. Oldham (Phil. Trans., I900), in a paper on the "Propagation of Earthquake Waves," came to the conclusion that the evidence pointed to a central metallic core, and to the existence of marked differences in the physical constants of the core and the surrounding crust. $\mathrm{He}$, however, assigned a comparatively small radius to this core, viz., about 0.55 that of the earth.

I will now call your attention to the light thrown on this subject by the recent investigations of Prof. Milne. The difference in the rate of propagation of earthquake waves through the earth's interior and through the crust has led him to the conclusion that the material below a depth approximating to thirty miles is of a uniform nature, and that the change in physical constitution is abrupt at some such depth as that indicated. He writes as follows :-

"For chords which lie within a depth of thirty miles the recorded speeds do not exceed those which we should expect for waves of compression in rocky material. This, therefore, is a maximum depth at which we should look for materials having similar physical properties to those we see on the earth's surface; beneath this limit the materials of the outer part of this planet appear rapidly to merge into a fairly homogeneous nucleus with a high rigidity."

In the Transactions of the Royal Society for 1905 wil be found a paper by Lieut.-Colonel S. G. Burrard on "The Intensity of the Force of Gravity in India." Colonel Burrard writes as follows:- "Geodetical observations have shown that the density of the earth's crust is variable, but they have not given any positive indications of the depths to which these observed variations extend. All calculations of the depths of subterranean variations in density and of the mountain compensation have, therefore, to be based on arbitrary assumptions of depth. The fact that the plumb-line seems generally to respond readily to the results given by the pendulum perhaps justifies the inference that the observed variations in the density of the earth's crust are not deep-seated. If an abnormal amount of matter exists in the crust near the surface, it wil exercise direct effects upon plumb-lines and pendulums in the vicinity, but if it lies at a great depth its effects, especially on plumb-lines, will be less perceptible.... I have taken several instances of abnormal pendulum results from table, and have found in each case direct response from the plumb-lines at neighbouring stations. This conformity could hardly ensue if the variations in density extended to greater depths than thirty or forty miles. Our results do not justify us in asserting that no deep-seated variations in density exist, but they do justify the belief that the variations in density which have been discovere are apparently superficial."

It is interesting to notice the agreement between results drawn from such dissimilar sources. On the one hand we have had to deal with effects produced by almost inconceivably small particles travelling with immense velocity on the other, with effects dependent upon the behaviour

No. 19I9, VOL. 74] of "the huge terrestrial globe." That travellers starting from such opposite extremes should arrive at a common destination is in itself a striking example of the scope and accuracy of the work undertaken by investigators in physical science.

It is possible that the evidence from each source, considered independently, might be regarded as inadequate, but the cumulative effect is sufficiently strong to justify the belief that some marked physical change in the constitution occurs at a depth of some thirty to fifty miles.

At all events, we have indications that, with the exception of a comparatively thin crust, the earth consists of a non-radio-active substance with a rigidity approaching that of steel, with an average temperature in the neighbourhood of $1500^{\circ} \mathrm{C}$., and a density at that temperature of about $5^{\circ} \cdot 6 \mathrm{C}$.

An interesting question awaiting solution is the probable constitution of this core.

The above is but an example of the many fascinating problems upon which fresh light has been thrown by the revelations of recent discoveries in radio-activity, and the temptation to dwell on such themes is correspondingly great: but I feel that such a task should be committed to hands more capable than mine.

Fortunately, in the discussions which will take place during our meeting ample opportunity will be afforded those entitled to speak with authority. Nevertheless, there are one or two further aspects of the matter which I will venture to touch upon, although but an onlooker. I would, first of all, urge the importance of a study of what may be termed the natural history of the elements. We require more information as to their comparative proportions in different localities. The fact that, given the amount of uranium in a sample of native rock, we can predict with certainty the amount of radium contained in the same specimen is of startling significance.

The natural law which governs the proportions of these two substances may have a far wider reaching scope than we at present suspect. Nature appears to present to us a grouping which would not naturally have occurred to the mind of the chemist; lead and silver, copper and gold, and, again, platinum and iridium, seem invariably to be introduced to us by Nature as if bearing to each other some kind of blood relationship.

The facts we already possess seem dimly to indicate some close relation between elements which we have hitherto considered as outside the bounds of consanguinity, and for a fuller knowledge of this important branch of natural history we require the assistance of the practical engineer, the geologist, the metallurgist, and the chemist.

Many of the results arrived at by the investigators into the phenomena of radio-activity can apparently only be verified by the lapse of considerable intervals of time. It is probable, for example, that we can estimate with some degree of accuracy the time required for the dissolution of half a given mass of uranium or radium, but the complete verification of our inferences must probably be left to a future generation. If we accept this view, it is our duty to provide our successors with data on which their conclusions may be based. If, for example, carefully determined masses of the more radio-active substances could be placed in such circumstances as to remain untouched until the meeting of this Association some hundred years hence, our successors, who would doubtless be equipped with apparatus of research more accurate and more sensitive than any in our possession, would at all events be placed in a position to establish by direct methods the accuracy of inferences based upon the experimental data now at our disposal. This task is one which, it appears to me, might well be undertaken by Section A, and I trust that this suggestion may be held worthy of some consideration.

It appears probable that one gram of radium diminishes in weight by about half a milligram per annum; hence, if the funds of this Society admitted of the imprisonment of some definite mass of radium, our successors a hundred years hence would, even if they possessed only the apparatus now at our disposal, be able to determine its loss with sufficient accuracy to enable them to verify the truth of the conclusions arrived at by the physicist of to-day, while the investigation of the radio-activity of 
the residue would possibly throw light on many problems now awaiting solution.

It would appear that if we made a similar imprisonment of uranium, a like degree of accuracy would not be attainable until after the lapse of half-a-million years, and I am afraid that our interest in the work of our successors cannot be expected to cover so long a period. Nevertheless, it is probable that the presence of the products of decomposition could easily be detected after the lapse of a comparatively short interval of time.

The experiment might well be extended so as to include examples of all the elements capable of such treatment; and with each prisoner should be placed a full record of its physical constants, such as mass, density, electrical conductivity, specific heat, \&c., with a clear indication of what is believed to be the probable accuracy of such determination.

During the past twenty-five years much thought has been devoted to the accurate determination of certain physical constants. This is very apparent in the case of one of the most important-namely, that commonly termed the "mechanical equivalent of heat," or, as I prefer to define it, the "thermal equivalent of energy." When Lord Kelvin addressed you in I88I, I think it probable that he would have indicated the value obtained by Joule-viz., 772.6 foot-pounds-at Manchester, as the quantity of work required to raise the temperature of one pound of water through $\mathrm{I}^{\circ} \mathrm{F}$. at $62^{\circ} \mathrm{F}$. It is true that the results of Rowland's classical investigation were published in 1880 and $\mathrm{I} 88 \mathrm{I}$, but the discrepancy between his conclusions and those of Regnault regarding the change in the specific heat of water at temperatures between $0^{\circ} \mathrm{C}$. and $30^{\circ} \mathrm{C}$. introduced an element of uncertainty.

As a consequence of this discrepancy much experimental work on the subject has been performed in the last quarter of a century, and I think it may be said without hesitation that the value of this important constant is now ascertained with an accuracy of about one part in 2000 . The amount of labour which has been employed in the determination of this thermal constant is extraordinary, and, as I have pointed out elsewhere, it well illustrates the cosmopolitan character of scientific investigation.

I have given reasons (Griffiths, "The Thermal Measurement of Energy") for specially selecting for consideration the determinations of Rowland, of Bartoli and Stracciati, of Ludin, of Callendar and Barnes, of Schuster and Gannon, and I have ventured to add my own. Thus Baltimore, Pisa, Zurich, Montreal, Manchester, and Cambridge have all contributed to the solution of the problem, and we may now with some certainty say that $777 \cdot 7$ footpounds at Greenwich are very closely the equivalent of the amount of heat required to raise $\mathrm{I} \mathrm{Ib}$. of water through $x^{\circ}$ on the hydrogen scale at $63^{\circ} \cdot 5 \mathrm{~F}$.

It may possibly appear that the result just quoted is a somewhat poor return for the expenditure of so much thought and labour. I would call attention, therefore, to the fact that the value of this equivalent is dependent on the measurements of many other natural constants; hence any agreement between the results obtained by the observations of Rowland and some of the other observers I have mentioned would only be possible in the absence of errors of appreciable magnitude in the determinations of mass, of change of temperature, and of electrical resistance and current. Certain discrepancies have led to the discovery of a hitherto unsuspected cause of inaccuracy, especially in the determination of temperature, and thus the inquiry has rendered valuable service in many branches of physical inquiry.

For example, so far back as 1893 I ventured upon a prophecy that the value assigned to the E.M.F. of a Clarke's cell was somewhat too high, and that it was possible that 1.4328 represents more truly the potential difference of a Clarke's cell at $15^{\circ} \mathrm{C}$. than the ordinarily accepted value of 1.4342. In the report of the Electrical Standards Committee for 1897 will be found a discussion of this matter, and one of the consequences of the deliberations of that Committee is to be seen in the ampere balance now standing in the National Physical Laboratory.

The results of the observations obtained by this instrument will, I believe, shortly be published by Prof. No. I9I9, VOL. 74$]$
Ayrton and Mr. Mather, but I am at liberty to state that, so far as the observations have been reduced, they point to the conclusion that the prophecy to which I have referred is closely fulfilled. We may say, therefore, with some confidence that the values of those units which form the basis of our system of electrical measurement are not only practically determined with a high degree of accuracy, but that also our measurements of temperature and of energy are placed on a satisfactory footing.

The last few years have been fruitful in revelations which not only profoundly affect the views of students of science, but also are of such a nature as to catch the eye of the public. In some cases the applications of these discoveries to the purposes of mankind have been evident and immediate. Every well-equipped hospital possesses apparatus for the production of Röntgen rays, and I suppose that every bluejacket in the Navy has some degree of acquaintance with those applications of science which have resulted from the discovery of Hertzian waves.

The ambition of the student is naturally fired by such examples, and there is a possible danger that the plodding but absolutely necessary work of accurate measurement may suffer by neglect. I therefore venture to repeat the well-established axiom that our advance in scientific knowledge is a function of accurate measurement, and that the student who devotes his energy to the determination of some physical constant is probably giving a "point of departure " to the pioneer. For it must ever be remembered that to the scientific investigator the rule of three has ceased to hold any significance.

When Lord Rayleigh discovered that the mean weight per litre under standard conditions of chemical nitrogen was $\mathrm{I} \cdot 25 \mathrm{I}$, and that of atmospheric nitrogen was $\mathrm{I} \cdot 257$, the believer in the rule of three would have been unlikely to suspect that this difference of 0.006 would supply the clue which led Lord Rayleigh and Sir W. Ramsay to the discovery of a new element, a discovery which in its turn led to others of possibly even greater importance. For all we know the next decimal place in any hitherto accepted value may afford another example of the truth of the statement that a part may be greater than the whole.

At the time when Lord Kelvin delivered the Address to which I have already referred the truth of the second law of thermodynamics was probably not so generally accepted as is the case at the present time. Each apparent example of violation of that law has on closer examination proved to be additional evidence of its validity. We seem unable to find those "sorting demons" of Maxwell's the existence of which appears necessary for its violation.

Mr. Campbell recently expressed doubts as to the application of thermodynamic considerations to osmotics. $\mathrm{He}$ contended that the errors in the determination of osmotic pressure were greater than those which could be attributed to experimental sources. Now, the theoretical relation between osmotic pressure and the freezing-point is based directly on thermodynamic considerations, and it was because I entertained a belief that the most direct evidence of this much-debated matter could be obtained from the observation of the freezing-point of a very dilute solution that I embarked on a series of somewhat elaborate experiments during the years 1897 to 1901. My removal from Cambridge and the death of my assistant, Mr. C. Green, compelled me to leave that inquiry in an unfinished condition. Nevertheless, I had investigated the depression of the freezing-point in certain solutions varying in strength from 0.0003 to $0.025 \mathrm{gm}$.-molecule per litre.

Subsequently to my departure from Cambridge $\mathrm{Mr}$. Bedford re-erected the apparatus in another building. After having surmounted great difficulties, he repeated many of my experiments, and he informs me that the numbers he has so far obtained are in almost entire agreement with those previously obtained by me. The molecular depression in the case of cane sugar I found to be $r .858$, of potassium chloride 3.720 , and I understand that $\mathrm{Mr}$. Bedford's experiments agree with these results with a discrepancy of less than I part in rooo. The most probable number obtained from theoretical considerations would be in the former case 1.857, in the latter 3.714. As Mr. Whetham has pointed out, unless there is some balancing 
of opposite errors of a very improbable nature, it is difficult to imagine a more direct vindication of the application of thermodynamic considerations to the phenomena of solution. I may add that I also examined correspondingly dilute solutions of sodium chloride, barium chloride, sulphuric acid, potassium bichromate, magnesium chloride, and potassium iodide; but, owing to the circumstances to which I have referred, I was unable to repeat these experiments in such a manner as to enable me to attach great importance to the resulting figures. Nevertheless, I obtained values which strengthened the conclusions to which I was led by the more exhaustive examination of the dilute solutions of sugar and potassium chlorioe.

So far back as the Liverpool Meeting of this Association I expressed a hope that the experimental difficulties of the direct measurement of osmotic pressures would be overcome, as such direct measurement would afford the most useful data by means of which to obtain further light on the much-vexed question of the nature of solutions. I remember, also, that it was the general opinion of those who had given attention to this matter that the experimental difficulties were insuperable.

I am glad, therefore, to have this opportunity of stating my high appreciation of the manner in which Lord Berkeley and $\mathrm{Mr}$. Hartley have grappled with the diffculties of this investigation. They have proved that the osmotic pressure obtained by direct measurement agrees with that derived from vapour-pressure observations to within less than 5 per cent. ${ }^{3}$ The agreement is of great importance, as it diminishes our doubts as to the extent to which the imperfections of semi-permeable membranes may affect the validity of results dependent upon their behaviour, and points to the possibility of determining the osmotic pressures of concentrated solutions by measurement of their vapour pressures.

I trust it will not be thought out of place if I here refer to the interesting correspondence which has recently appeared in NATURE on the thermodynamic theory of osmotic pressure, and the allied, but by no means identical, problem of the difference between electrolytic and nonelectrolytic solutions.

On the one side we have Prof. Armstrong, whose chief desire appears to be the vindication of the moral rharacter of what he terms "the poor molecule"; and Mr. Campbell, whose doubts concerning the second law of thermodynamics are closely connected with a lurking belief in the existence of Maxwell's "sorting demons"; and by way of reserves we have Prof. Kahlenberg, who contends that " thermodynamic reasoning cannot be applied to actual osmotic processes" on account of the "selective action of the membrane" and "insists that the formation of crystals from a solution or the concentration of a solution by evaporation are not osmotic processes."

On the other hand we have Mr. Whetham, who, I confess, seems to me to be capable of holding his own without need of reinforcements. He has pointed out that confusion has arisen from the use of the term "osmotic pressure " to denote the actual pressure experimentally realised in certain conditions, as well as the ideal pressure required in thermodynamic theory. With regard to the theory of electrolytic dissociation, Mr. Whetham shows that the fact that the velocities of the ions are constant in dilute solutions and decrease slowly with increasing concentration, while the conductivity of a dilute solution is at most proportional to the first power of the concentration, appears irreconcilable with any assumption as to the existence of the active part of an electrolyte in the form of combined molecules when in solution. I would here join with $\mathrm{Mr}$. Whetham in the request that those who oppose the theory of ionic dissociation would state their views as to the mechanism of electrolysis, and their reasons for supposing that the application of the principles of thermodynamics to the phenomena of solution is unjustifiable.

Prof. Armstrong remarks that it is unfair to "cloak

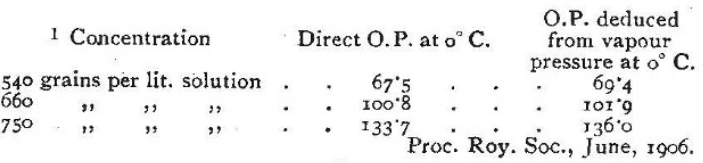

No. 1919, VOL. 74] the inquiry by restricting it to thermodynamic reasoning, a favourite manœuvre with the mathematically minded." $\mathrm{He}$ adds that such a course may satisfy the physicist, but " is repulsive to the chemist."

The inquiry, "Why is the application of thermodynamic reasoning repulsive to the chemist?" naturally suggests itself. I confess that at one time I regarded the extreme advocates of the theory of ionic dissociation with a certain amount of suspicion, but I think that most of those who have studied the evidence now at our disposal, or who have been engaged in experimental investigation into this inter esting branch of physics, cannot fail to agree with $\mathrm{Mr}$. Whetham that, as regards the fundamental conceptions of the theory, "the cumulative evidence seems overpowering." At all events, we may consider that the application to the phenomena of solution of reasoning based on thermodynamic considerations is justifiable, until we are presented with stronger arguments than those based on the repulsiveness to certain chemists of the conclusions to which it leads, or the doubt it throws upon the activities of Maxwell's demons and the selective action of semi-permeable membranes.

I will now trespass upon your forbearance and pass from the consideration of such special departments of natural science as usually engage the attention of members of this Section to some more general considerations, which naturally arise in any comparison of our knowledge of today with that which we possessed when we last met in this city.

It will, I think, generally be admitted that during the last twenty-five years the increase in our " natural knowledge" has been greater than in any previous quarter of a century.

Day by day we are adding new facts to our storehouse of information, until it has now become impossible for the individual to have more than a superficial knowledge of the contents of the building. And although this accumulation is one which we may well regard with satisfaction, it necessarily gives rise to difficulties unfelt by our predecessors.

I venture to indicate one of such difficulties, one which has been brought home to me both by my experience as an examiner and by the fact that during the past few years $I$ have had to preside over many meetings of examiners, and to mark the effect of examinations on the teaching in our universities.

We now expect a student to acquire in a three years' course a far greater amount of information than was considered necessary, say, twenty-five years ago. The attention both of the teacher and of the taught is naturally directed to those extremities of the branches of science in which the growth has been most marked in recent years, and I venture to think that there is in consequence some danger of our neglecting the roots of the whole matter. Compare, for example, a Final paper in chemistry in any one of our universities with its predecessor of a quarter of a century ago.

The enormous advance of organic chemistry has necessarily reacted on the examinations, and thus the student is unable to devote an adequate proportion of his time and attention to the foundations of the subject. The same remark applies in the domain of physics. There is a danger, therefore, of our educational edifice becoming topheavy.

I have heard complaints, on the one hand, from the examiners that while the candidates frequently exhibit considerable knowledge of the most recent scientific developments, they show a lamentable ignorance of the simple phenomena and the principles they illustrate. On the other hand, I have heard from candidates that many of the questions were too simple-that they were concerned with principles and facts to which their attention had not been directed since they first began the study of natural science.

My own experience has been that the simplest questions are those answered in the least effective manner. A candidate unable to give satisfactory illustrations of Newton's Laws will discourse upon the mass of an electron or the nature of the Röntgen rays, and attempt the solution of problems on such subjects as Hertzian waves and electric convection. 
I hope that the attention of both examiners and teachers nay be directed to the best methods of dealing with what appears to me to be not only a serious but an increasing evil.

To pass from one of the inconveniences which inevitably arise from growth, it is pleasant to dwell upon its more gratifying consequences.

Perhaps one of the most marked characteristics of the progress of science in recent times is the increasing public appreciation of the importance of original investigation and research.

The expansion of the university colleges in number and importance has greatly assisted and quickened this movement.

Twenty-five years ago there were comparatively few laboratories which held out any possibility of research to the English student. True, there were giants in those days, men, as a rule, working under difficulties greater than those encountered by their successors of to-day. The better equipment of our laboratories and the growth in the number and activity of our scientific societies have played no small part in stimulating public interest. Nevertheless, much remains to be done. Those who have read Prof. Perry's somewhat pessimistic words on England's neglect of science must admit that, however rapid our progress, the British people have not yet so fully awakened to the national importance of this question as some of our competitors.

The idea that a degree is one of the chief objects of education yet lingers amongst us. The conviction that it is a national duty to seek out and, when found, utilise the latent scientific ability of the rising generation for the purpose of adding to our stores of natural knowledge still needs to be brought home to the "man in the street." And here I would venture to indicate my personal belief in the necessity of more free communication between the laboratory and the market-place. It is possible that the language of science is becoming too technical, and that the difficulties with which scientific inquirers have been faced in past times have tended to habits of exclusiveness. For example, complaints are frequent that our manufacturers are less alert in grasping the practical applications of scientific discovery than their competitors in Germany and the United States. I confess, however, that it seems to me possible that the fault is not altogether on the side of the manufacturers. We want missionaries to preach the doctrine that one of the greatest of national assets is scientific discovery. If we can convince the men of business of this country that there are few more profitable investments than the encouragement of research, our difficulties in this matter will be at an end.

It is my lot to serve on the education committees of three county councils, and I have been much struck by the readiness of the members of those bodies to extend such encouragement whenever it has been possible to convince them that the results may conduce to the prosperity, the comfort, and the safety of the community.

It has also been my privilege to address meetings of the men who work in the coalfields of South Wales. I have attempted to direct their attention to the advantages which they have derived from the labours of those who have endeavoured to probe the secrets of Nature in the laboratory; I have tried to show how discoveries based on the researches of Humphry Davy, Faraday, Joule, for example, have not only diminished the dangers to which miners are exposed, but have also, by increasing the demands upon our stores of energy, given employment to thousands of their fellow-workers.

$\mathrm{My}$ experiences lead me to the belief that these men are ready to support the action of their representatives in extending support and encouragement to all efforts to assist the advance of scientific discovery.

It is possible that in dwelling on this matter I am trespassing on your forbearance, but I cannot resist this opportunity of pleading for the extension of your sympathies beyond the walls of the laboratory. The old toast, "Here's to science pure and undefiled; may it never do a ha'porth of good to anybody," may possibly be an excellent one in the laboratory; for, so far as I know, no great scientific principle has ever been established by

No. I9I9, VOL. 747 labours prompted solely by desire for financial gain. Nevertheless, if we wish for the support of our fellowcountrymen, that toast is not one for public dinners. There is no scientific society which is brought into such close oontact with the public as is the British Association, and affiliated with that Association are some scores of local scientific societies, containing many thousands of enthusiastic observers and inquirers. If this great organisation were seriously to take up the task of bringing home to the minds of the people of this kingdom the enormous value of the results of scientific inquiry, I believe it might be possible to change the indifference and apathy of our public bodies into active interest and encouragement. If each affiliated society would institute a series of public nontechnical lectures, of such a nature as to bring home to the minds of the hearers some comprehension of the results of the work of Faraday, of Wheatstone, of Pasteur, of Maxwell, of Lister, and of Kelvin, the change in the public attitude would be real, evident, and fruitful.

In conclusion, one is tempted to seek for the underlying cause of the acceleration in the rate of advance of natural knowledge. Is it to be found in the increase in power of the human intellect, or the diversion into one particular channel of activities previously otherwise employed? It is possible that the human intellect has, by the processes of evolution, become more powerful, and that man's ability to decipher the secrets of Nature has thereby increased. I think, however, that it would require a bold advocate to support this thesis. If any such mental evolution has taken place, it is strange that it should be restricted to one particular sphere of activity. Are our poets and authors of to-day greater than Homer, our statesmen than Pericles? Or, passing into the domain of science, can we say with confidence that, in pure power of reasoning, Maxwell was undoubtedly the superior of Archimedes?

I have elsewhere indicated what appears to me to explain the mystery of this acceleration, namely, the extension of our senses by mechanical appliances. When we supplement our eyes by the bolometer and the electric coherer, the range of our vision is augmented a thousandfold. By the use of the electroscope and the galvanometer we have extended our senses of sight and touch until we can detect the presence of an electron.

Having realised the imperfection of our faculties, we have called upon Nature in all departments of science to supply our deficiencies, and are thus enabled to walk with confidence where previously all seemed dark.

From the time of Archimedes to that of Bacon we despised Natural Knowledge while we deified intellect and authority; hence for nearly 2000 years our record was one of retreat rather than advance. When the philosopher left his study and applied his powers of observation to the phenomena of the universe, progress became a reality, and thenceforward the march of discovery has known no backward step. We have therefore every reason to believe that when the Association again visits this ancient city our President will be able to chronicle an increase in Natural Knowledge even greater than that which has been one of the distinguishing characteristics of the last quarter of a century.

\section{SECTION B.}

CHEMISTRY.

Opening Address by Prof. Wyndham Dunstan, M.A., LL.D., F.R.S., F.C.S., President of the Section.

\section{Some Imperial Aspects of Applied Chemistry.}

THE President of the Chemical Section of the British Association must always have a large choice of subjects for his Address. He may attempt to review the chemical progress of the year, or to give an account of researches in that division of the science in which he is most interested. He may deal with the ever-recurring problems of education; or, again, he may draw attention to the importance of our science in one or other of its many relations to National and Imperial affairs. I have decided to adopt the last course, and to invite your attention at York, where several tropical products furnish the basis of important industries, 
to the intimate connection of our science with the problems that await solution in connection with the utilisation of the raw materials and economic products of our Colonies, and especially those of our tropical Possessions. There is a pressing need that the Imperial Government should recognise much more fully than it has hitherto done, and at least as fully as foreign Governments are already doing, the claims of scientific investigation to be regarded as the pioneer instrument of this work, and as the essential first step in the material and commercial development of our Possessions.

Although my remarks will be chiefly directed to the importance of chemistry in this connection, my plea will be more general. It is that the scientific method of experimental research should be systematically applied in each division of the sciences concerned. In the case of raw materials, however, whether vegetable or mineral, their commercial value must depend chiefly, if not entirely, upon their composition, and sooner or later the method of chemistry must therefore be applied.

In determining the value of the mineral resources of a country other specialists are also concerned, and the assistance of the geologist, the mineralogist, and eventually of the metallurgist may be required. Similarly with vegetable and agricultural products the services of the economic botanist and of the entomologist will be needed. It will therefore be necessary for me in dealing with the subject as a whole to touch upon several aspects in which other sciences are concerned, and with which the science of chemistry must cooperate in attaining a practical endnamely, the material development of the countries concerned. I need make no apology for many allusions to scientific agriculture, for this subject is this year attached to this Section, and indeed the science of chemistry is of fundamental importance to agricultural practice both at home and in the tropics.

In the first place I must ask you to allow me to say a few words as to the very wide interests that are involved in the proper solution of the problem of colonial development.

It is all-important that the wage-earning community of this country should have an adequate supply of tea, coffee, cocoa, rice, tobacco, and other commodities, and that our manufacturers should be able to count upon a regular supply of cotton, jute, rubber, and other raw materials as far as possible under their own control. All these products are derived almost exclusively from the tropics, and experience shows that it is a great disadvantage to the manufacturer not to be able to exercise control in the direction of securing the regular production of these materials, and especially not to be able to avoid the great and sudden fluctuations in their price, which are often the result of financial speculation on the part of a foreign capitalist who has secured the control of the output of a foreign country.

The almost entire dependence of the great textile industries of Lancashire upon the cotton crop of the Southern States of America has placed this industry at the mercy of American speculators, whose tactics may lead, as in x 903 , to such a rise in the price of the raw material as to render it imperative for the manufacturer to close his mills, and by throwing large numbers out of employment to bring poverty and misery to many thousands of people.

The great principle which must now necessarily guide our system of administration and expenditure in our tropical Colonies and Protectorates has as its purpose the utilisation of natural resources and the creation and development of native industries with the aid of European supervision and advice. Adequate supplies of produce, natural and agricultural, will thus be ensured to British manufacturers and consumers from territories within the administration of the British Crown. This principle of employing our "undeveloped estates" for the advantage of our manufacturers and consumers, and at the same time for the benefit of the natives who inhabit these countries, was put into action by $\mathrm{Mr}$. Chamberlain during his long tenure of office as Secretary of State for the Colonies, and this recognition of a vitally important principle must always be associated with his name.

Excepting India and the self-governing Colonies, the No. I9I9, vol. 74$]$
Crown Colonies and Protectorates, for which alone the Imperial Government is directly responsible, include an area of about two and a half million square miles and a population of about forty millions. The value of these possessions to us at the present time may be judged from the value of their import and export trade with the United Kingdom. The value of the exports of these countries in I904 was estimated at about four and a half million pounds sterling, and the imports from the United Kingdom at about twelve and a half million pounds sterling. In gauging the importance to this country of the development of these Possessions, the export trade of which is only in its infancy, it should be remembered that the profits arising from the export as well as from the import trade are chiefly domiciled in this country; since practically the whole of this trade is in the hands of British merchants, and the entire profits, including those of shipping, \&c., are therefore subject to our national system of taxation, and represent a very substantial annual contribution to the British Exchequer.

It is therefore only reasonable that a certain sum should be expended from British funds to aid the applications of science to the commercial development of these Possessions. Such an expenditure in the light of the facts to which I have drawn attention may be regarded as an investment with the certainty of a profitable return.

I have thought it necessary to give this brief account of the position of our still undeveloped Crown Colonies and Protectorates and the national importance to us of their systematic development before proceeding to the principal subject of this Address, which is to emphasise the aid which science in several of its branches can render to this work of development, and especially the science of chemistry, the capacities of which in this connection have so far not been sufficiently recognised.

The importance of utilising our own tropical Possessions as sources of the raw material required by the manufacturer is now generally recognised, and very considerable progress has been made in recent years. The tea produced in India and Ceylon has largely superseded the China tea formerly used in this country. Similarly, coffee is extensively grown in India, in the West Indies, and in several of our African Possessions. The jute cultivation in India has been very successful, and the demand for this fibre is so great that the question of its cultivation in our West African Colonies is now under consideration. India-rubber, hitherto chiefly obtained from South America, is of increasing importance as a commercial article, and the South American tree has been introduced with success in Ceylon, the Straits Settlements, and the Federated Malay States, which are rapidly becoming important rubber-producing countries the produce of which is competing successfully with that of South America. The cultivation of cotton, hitherto principally carried on in the United States, is being vigorously proceeded with in India, the West Indies, and in West Africa, as well as in Egypt and the Sudan, and we may look forward in the future to these countries supplying the British manufacturer with a large proportion, if not the whole, of the cotton he requires.

There are, however, vast resources, both mineral and vegetable, in our Colonies and Protectorates which are awaiting development for an exact knowledge of their composition and properties, which can only be ascertained by scientific means and chiefly through chemical investigation, whilst the British manufacturer is in need of increased and better supplies of the raw materials on which his industrial activity depends. This demand for increased supplies now affects nearly every industry in this country. Rubber and fibres are well-known examples; oils and fats for the manufacture of soap and perfumes; and tanning materials, as well as numerous minerals, are other instances in which our manufacturers are at present anxious to discover new sources of supply. These sources can only be discovered and their value ascertained by properly directed scientific investigations.

We have heard much recently respecting the assistance which science can bring to the maintenance and development of the industrial efficiency of this country, and the Imperial Government is being urged to give its help especially by providing increased facilities for the educa- 
tion of scientific men, competent to aid the manufacturers of this country in improving their methods and processes. In this work the science of chemistry is one of the most important. There is scarcely an industry to which it is not able to render immense service. Within recent years this fact has slowly gained recognition, and the principle of State assistance to industry is virtually admitted, both in respect of education and of research. The most recent examples of a recognition of the principle are the grants made from the National Treasury to the new Technological College at South Kensington and to the National Physical Laboratory.

Not less important than the service which science can render to existing industries and their extension is that which it can contribute to the Imperial problem of ascertaining and rendering available for the manufacturer the vast undeveloped resources of our own Possessions. Our own experience and the example of other countries have shown that such work cannot be systematically carried on by private enterprise. Upon its successful accomplishment depends, not only the unrestricted supply of the necessary raw materials for which the manufacturer looks in increasing quantity, but also the prosperity of the country which produces these materials. This success can only be brought about by a combined effert on the part of the manufacturer and of the Government. The manufacturer can provide information as to the materials he needs. The preliminary work of discovering suitable material by scientific means, as several foreign Governments have already recognised, must be endowed, directed, and carried on with Imperial funds. It cannot be expected that private enterprise will take steps to explore the resources of little-known countries on the chance of a particular material being discovered, nor can the work, as a rule, be successfully done by this means. Experience shows that the most effective manner of promoting the commercial development of a new country is for the Government to carry out systematically with its own officers the preliminary work of exploration and examination of the natural resources, with the aid of such technical advice as may be necessary from manufacturers and users, and then, having established the fact that particular products of value can be found or cultivated in a given country, to leave commercial enterprise to do the rest. By action on these lines immense progress is being made in French, German, and Dutch possessions, whilst the United States Government has taken similar action with the Philippines. In our own case, where this work exists it is in most cases in a more or less embryonic condition, and lacks the organisation which is necessary for success.

In many of our Crown Colonies and Protectorates there already exist, or are in the process of organisation, agricultural and other scientific departments, many of which include officers who are engaged in the work of exploring and developing the vegetable resources of these countries especially by experimental planting. Chemists are attached to some, but not to all of these departments. In the West Indies the valuable work accomplished by Prof. Harrison, Mr. Francis Watts, Prof. Albuquerque, Prof. Carmody, and $\mathrm{Mr}$. Cousins is well known, and illustrates the great services which the science of chemistry may render, not only to tropical agriculture, but to every branch of economic development. It is clearly desirable that at least one scientific department should be attached to the Government of each of the principal Crown Colonies and Protectorates. As a rule, it is convenient that this should be an agricultural department with the services of a scientific chemist at its disposal. In a tropical climate, and with limited appliances at his command, it must be admitted that a chemist is severely handicapped, and, as a rule, he cannot be expected at first to be able to do much beyond the comparatively simple and preliminary work, chiefly analytical, which, however, in a little-known country is of the greatest importance to an agricultural department. In addition, he would have to deal with the composition of natural products of all kinds, both vegetable and mineral, as well as with the improvement of native industries. If the chemist is able to refer complicated or special investigations to a central department at home, and is provided with assistance in the routine work, he would be in a position to No. I9I9, vOL. 74] undertake the scientific investigation of a selection from the numerous problems with which a chemist will be confronted.

A chemist working in the spirit of an investigator will be able to render special services to the cause of tropical agriculture, and it is therefore of importance that in future the men appointed to these posts should be chosen as far as possible on account of the promise they have shown as investigators. The determination of the constituents of little-known indigenous plants as the first step towards ascertaining their economic value is another department of work which cannot be carried out without a chemist, and the same applies to the examination of poisonous plants, and also of minerals, in addition to the determination of the composition of foods and feeding stuffs.

Tropical agriculture is a subject which is now of the first importance, especially in those countries in which our policy is to depend on a native population for the actual cultivation of the soil. We have two functions to perform in our position as supervisors: the one is to ascertain the nature and capabilities of the soil by actual experiment, for which well-organised experimental stations are a necessary part of every agricultural department; the other duty is to convey to the natives, chiefly by means of demonstration, the results of this experimental work, so that they may be persuaded to make it a part of their agricultural practice.

Work on these lines is being done under Government auspices in the French and German Colonies, and I may allude to the French successes in Algeria, in Senegal, and in the Sudan, and to the advances made by Germany in East Africa. These achievements are mainly due to a policy of continuous scientific work on agricultural lines. We shall have the privilege of hearing from Dr. Greshoff, the eminent director of the Colonial Museum at Haarlem, an account of the chemical investigations which are being carried out in connection with Java and the Dutch East Indies.

In many of our own Colonies and Protectorates active agricultural departments, equipped with the means of experimental working, are only now in process of organisation. One of the most recently organised of these is that of the Transvaal, which, at Lord Milner's initiation, has been completely equipped on the lines of that model for all such effort, the agricultural department of the United States. This department has as its chief chemist $\mathrm{Mr}$. Herbert Inglis, of the Yorkshire College, now the University of Leeds.

If we are to compete successfully with foreign countries it is necessary that the position of science in relation to tropical agriculture should be definitely recognised. The days when a botanical garden served the purpose of an entire scientific establishment in a Colony have passed away, and we now require, in order that a proper return should be obtained, and the natives assisted in their agricultural practice, a scientific department with a proper complement of specially trained officers, including a consulting chemist, other specialists being added to the staff as the requirements arise. These officers should be remunerated on a scale likely to attract some of the best educated men from this country, which is at present far from being the case.

It would be out of place to discuss here the detailed organisations of these scientific departments. I merely desire to urge the necessity of their functions being extended, and of their receiving adequate financial support.

It is important that the scientific work which is being accomplished by these various departments should be brought to a focus, and that the results obtained in one Colony should be available for the information of the departments in other Colonies. The work of all such establishments requires to be unified by cooperation with a Central Department which can extend the investigations conducted in the Colonies, carry out investigations and inquiries which cannot be undertaken on the spot, maintain the necessary touch with the manufacturers, and coordinate the work undertaken and the results obtained in each of the separate Colonial establishments and systematically collate it, so that each may be aware of the results that are being obtained in other countries. 
In our African Possessions at present the same investigations and inquiries have to be conducted independently, and often without the knowledge that the problem in question has been already solved.

Another increasingly urgent duty of the Central Department is to inform the Colonial establishments of the results of the work which is being conducted in foreign countries, and of the progress which is being made in the utilisation of raw materials all over the world, and to bring to their notice the constantly changing requirements of the manufacturers and users of raw materials.

So far as botany is concerned, this coordination has been to a large extent effected through the agency of the Royal Gardens, Kew, which is in touch, through the Colonial Office, with all the botanical gardens in the Crown Colonies and Protectorates. In chemistry, as well as in certain other subjects, these duties have been performed in recent years by the Scientific and Technical Department of the Imperial Institute, which is now working in cooperation, not only with the Governments of the Crown Colonies and Protectorates, but also with those of several of the self-governing Colonies, and also with the Scientific Departments which have been brought into existence in India, where at last the importance of scientific agriculture is receiving due recognition from the Government.

So little has hitherto been done in this direction that the number of problems requiring attention is exceedingly large; and even with a specially trained staff of workers and extensive laboratories, such as now exist at the Imperial Institute, it becomes necessary to select as the principal subjects for investigation those which are regarded by the Governments of the countries concerned as of the most practical importance, and in which the British manufacturer is at the moment most concerned. There must therefore remain a large number of materials of unknown composition and of problems of purely scientific interest which offer an attractive field for the chemical investigator. Already steps have been taken to provide for the investigation of these subjects by scientific men who are willing to undertake them in communication with the Institute. For example, Mr. A. G. Perkin, F.R.S., has been furnished with material which has led to the identification and determination of the constitution of the colouring matters of a number of plants which are employed as dyes in India and the Colonies. Prof. A. H. Church, F.R.S., has determined the composition of many new or little-known food grains. Dr. Crossley, Mr. Le Sueur, and Dr. Lewkowitsch have examined the constituents of a large number of fats and oils furnished by seeds of Indian and African origin. Dr. W. J. Russell, F.R.S., has been furnished with selected materials for examination in connection with his interesting investigations of those substances which affect the photographic plate in the dark, whilst the Hon. R. J. Strutt, F.R.S., has investigated the radio-activity of a number of new or little-known minerals containing rare earths. Last year more than 500 different materials and problems were submitted from the Colonies and India for investigation to the Scientific Department of the Imperial Institute, and each year there must remain an increasing number of interesting subjects which cannot be included in the Department's annual programme of work. Many of these would furnish excellent subjects for chemical research by advanced students in connection with the universities and technical colleges throughout the country. It is nearly always possible to arrange to furnish the necessary material for any competent worker to deal with. Next year a list of such subjects awaiting investigation will be available at the Imperial Institute for those in search of subjects for chemical research.

Whilst the investigation of some of these subjects may at once produce results of scientific value, many of them present difficulties in their investigation which are far more serious than those which attend the usual synthetical work in organic chemistry. I do not know of any more profitable experience for the advanced student who is already familiar with the principles of organic chemistry and of laboratory practice than the separation in the pure state of the chemical constituents of a plant and the determination of their chemical constitution. In inorganic chemistry the examination of a new mineral furnishes similar experience.

In carrying out research of the kind I am advocating, the chemical investigator will have the additional advantage of knowing that the scientific results he obtains will contribute to the knowledge of the resources of the British Empire, and possibly be the means of laying the foundations of new industries.

I need hardly remind chemists that some of the most important discoveries in our science, and many of those which have had the most profound influence on the de velopment of chemical theory, have arisen from the examination of the constituents of raw materials. The discovery of morphia in opium led to the recognition of the new class of alkaloids; the discovery of amygdalin in the bitter almond of the new group of glucosides; the investigation by Liebig and Wöhler of the chemical properties and composition of the essential oil of the bitter almond was largely instrumental in laying the foundations of modern organic chemistry; whilst it was during the examination of the constituents of bran that Fownes was led to the discovery of furfurol and the subsequent recognition of a new type of organic compound. In more recent times the examination of the constituents of oil of turpentine and various essential oils yielded by different plants has been the means of elucidating the chemical theory of the great group of terpenes, and latterly Harries's investigation of caoutchouc has led to the discovery of the ozonides which seem likely to be of much importance as a new means of determining the constitution of certain classes of organic compounds. Lastly, I may remind you that the discovery of helium might have been long delayed had not Prof: Miers drawn Sir William Ramsay's attention to the socalled nitrogen furnished by the mineral cleveite.

I have thought that it would be of interest on the present occasion if some account were given in the Section of the chemistry of certain of the raw materials employed in the principal manufacturing industries of the city of York. These industries are vitally concerned with an adequate supply of certain raw products of tropical origin, especially cocoa and gums. In connection with the first of these, which has hitherto been obtained chiefly from the West Indies, a new industry of cocoa production has sprung up in West Africa, notably in the Gold Coast and in Lagos. This West African cocoa presents some peculiarities which have rendered it desirable to examine the nature of its constituents. Gums of the nature of gum arabic are at present chiefly derived from the French Colony of Senegal. It is, however, clear from the examination of gum collected in West Africa that that country. and especially Northern Nigeria, will be able in the future to contribute to the needs of the British manufacturer, in addition to the Sudan, India, and Australia, which will also be able to make important contributions. In connection with the investigation of these gums derived from new sources at the Imperial Institute, the very remarkable observation has been made that certain gums from India and the Colonies possess the property of evolving acetic acid when exposed to the air. The chemical constitution of one of these gums has been fully investigated at the Imperial Institute by $\mathrm{Mr}$. H. H. Robinson, who will contribute a paper on the subject to the Section, in which he will show that the production of acetic acid is due to the elimination of an acetyl group by hydrolysis through the moisture of the air. $\mathrm{He}$ has also succeeded in elucidating to a large extent the chemical nature of the gum. Mr. Robinson will also make a report on the present position of the chemistry of gums, a class of substances the constitution of which is exceptionally difficult to unravel. Little, if any, advance has been made in recent years on the well-known researches of O'Sullivan.

There is no more important group of questions demanding attention from the chemist at the present time than those connected with the production of india-rubber or caoutchouc. An enormous increase in the demand for india-rubber has taken place in the last few years, and last year the production was not less than 60,000 tons. Until recently the supply of rubber came chiefly from two sources - the forests of Brazil, which contain the tree known as Hevea brasiliensis, furnishing the Para rubber of com-

No. I9I9, voL. 74] 
merce which commands the highest price, and the forests of Africa, where climbing plants, generally of the Landolphia class, also furnish rubber. The increased demand for caoutchouc has led to the extensive planting of the Para rubber tree, especially in Ceylon and in the Federated Malay States. Systematic cultivation and improved methods of preparation are responsible for the fact that the product of the cultivated tree, which begins to furnish satisfactory rubber when six or seven years old, is now commanding a higher price than the product of the wild tree in Brazil. It is estimated that within the next seven years the exports of cultivated india-rubber from Ceylon and the Federated Malay States will reach between ten and fifteen million pounds annually, and that after fifteen years they may exceed the exports of the so-called wild rubber from Brazil.

The services which chemistry can render to the elucidation of the problems of rubber production and utilisation are very numerous. Methods of treatment depending on a knowledge of the other constituents of the latex have led to the production of rubber in a purer condition. Much still remains to be elucidated by chemical means as to the nature of the remarkable coagulation of the latex. As is well known, the latex is a watery fluid resembling milk in appearance which contains the rubber, or, as I think more probable, the immediate precursor of rubber, together with proteids and other minor constituents. The constituent furnishing rubber is in suspension, and rises like cream when the latex is at rest. On the addition of an acid, or sometimes of alkali, or even on mere exposure, coagulation takes place and the rubber separates as a solid, the other constituents for the most part remaining dissolved in the aqueous liquid or "serum." The first view taken of the nature of the coagulation process was that, like the coagulation of milk by acids, it is dependent upon a process of proteid coagulation, the separated proteids carrying down the rubber during precipitation.

This explanation cannot, however, be considered complete by the chemist, and there are peculiarities connected with the coagulation of the latex which are opposed to the view that it is wholly explained by the coagulation of the associated proteids. The experimental investigation of the question on the chemical side is beset with many difficulties, which are increased if access cannot be had to fresh latex. A number of experiments were made at the Imperial Institute with latex forwarded from India. The difficulties contended with in preventing coagulation during transit were great, but in the case of the latex derived from certain plants these were to some extent surmounted, and the results obtained, especially with reference to the behaviour of certain solvents towards the latex, led to the conclusion that " coagulation" can take place after removal of the proteids, and that in all probability it is the result of the polymerisation of a liquid which is held in suspension in the latex and on polymerisation changes into the solid colloid which we know as caoutchouc. Weber, by experiments conducted in South America with fresh latex, arrived at a similar conclusion, which later workers have confirmed. Although the nature of the process is not yet completely elucidated, there is little room for doubt that the coagulation is due to the polymerisation of a liquid and possibly of a liquid hydrocarbon contained in the latex. For the chemist the important question remains as to the nature of this liquid from which caoutchouc is formed.

The chemical nature of caoutchouc is a subject which has attracted the attention of distinguished chemists from the middle of the eighteenth century, among them being Faraday, Liebig, and Dalton. Faraday was the first to examine the constituents of the latex of Hevea brasiliensis. It is only in recent years that our knowledge of the constitution of organic compounds, and especially of the terpene group, has rendered it possible to make any great advance. It is interesting to record that Greville Williams, in 1860. made most important contributions to this subject. He identified a new hydrocarbon, isoprene, as a decomposition product of caoutchouc, and recognised its polvmeric relation to caoutchouc.

The results obtained from the analytical side, and especially the formation of di-pentene and isoprene by pyrogenic decomposition of caoutchouc, had pointed to the fact that caoutchouc was essentially a terpenoid polymer of the formula $\mathrm{C}_{10} \mathrm{H}_{16}$. Harries finds, however, that the ozonide of caoutchouc, when distilled with steam, breaks up into lævulinic aldehyde, lævulinic acid, and hydrogen peroxide, and he concludes from this that caoutchouc is a polymer of a $1: 5$ dimethyl cyclo octadien. Whilst Harries's work has brought us much nearer the goal, and has led to the discovery of a new method of investigation through the ozonides, which is obviously of wide application, it cannot yet be said that the constitution of caoutchouc has been settled or its relation to the parent substance of the latex definitely established. It has still to be shown how a closed-chain hydrocarbon such as Harries's octadien can undergo polymerisation forming the colloid caoutchouc.

There are strong arguments for the view that the constitution of the parent substance present in the latex is nearly related to that of isoprene. This remarkable hydrocarbon of the formula $\mathrm{C}_{5} \mathrm{H}_{8}$, first obtained by Greville Williams from the dry distillation of rubber, is an unsaturated olefinic hydrocarbon which is found among the products, resulting from heating caoutchouc. It readily polymerises, forming di-pentene. Bouchardat noticed that this hydrocarbon obtained from the pyrogenic decomposition of caoutchouc furnished a substance identical with rubber when acted on by hydrochloric acid and under other conditions. To Wallach and also to Tilden is due the further important observation that when isoprene prepared from oil of turpentine is kept for some time, it gradually passes into a substance having all the characteristic properties of caoutchouc.

I have very briefly drawn attention to the present position of our knowledge of the chemistry of caoutchouc in illustration of the interest which attaches to the examination of vegetable products, and also because of the immense importance of the problem from the practical and commercial standpoint. Chemistry in this case holds the premier position in reference to this subject, and to a large extent may be said to hold the key to the future of the rubber industry in all its phases. The discovery of better methods of coagulation, preparation, and purification will be effected through chemical investigation, as will also the determination of the manner of utilising the various other plants which furnish rubber-like latices. That the physical properties of raw rubber, on which its technical value depends, are to be correlated with the chemical composition of the material there can be no doubt. The chemical analysis of raw rubber, as at present conducted, is, however, not always to be taken by itself as a trustworthy criterion of quality, and more refined processes of analysis are now needed. Although the finest caoutchouc for technical purposes is only yielded by some half-dozen plants, under the names of which these varieties of caoutchouc pass, there can scarcely be a doubt that the elastic substance in each case possesses a very similar, if not identical, chemical structure. Nearly all the latices and similar fluids furnished by plants contain more or less caoutchouc. Even opium, which is the dried juice of the capsule of the poppy, contains caoutchouc, whilst the opium yielded by certain Indian species contains a notable proportion. Chemistry must determine the means by which caoutchouc can best be separated from these relatively poor latices. In view of the increasing production of the nearly pure caoutchouc which is furnished by Hevea brasiliensis, Funtumia elastica, Castilloa elastica, Ficus elastica, and a few other plants which occur or can be cultivated in several of our tropical Possessions, the question is not a pressing one at the moment.

Moreover, it cannot be doubted that chemical science will sooner or later be able to take a definite step towards the production of rubber by artificial means.

The production of caoutchouc by chemical means has, indeed, virtually been accomplished in its formation from isoprene. The exact nature of this change has still to be determined. When this has been done it will only remain to cheapen the cost of production to make the manufacture of synthetic rubber a purely practical problem. I should be the last to discourage the great extension of rubber planting which is now taking place. It is warranted by

No. I9I9, vol. 74] 
the present demand for the material. It has also to be remembered that the actual cost of producing raw rubber, which is at present about one shilling per pound, will probably be reduced, and the market price of rubber may eventually be so considerably lowered that, as with quinine, the synthetic production could not be profitably carried on. That is a question which involves many factors at present unknown, and only time can decide. Chemists may, however, confidently predict that before the British Association again meets at York the synthetic production of rubber will be a fully accomplished fact.

As I have said, our science is concerned with nearly every problem connected with the great rubber industry, and in concluding these few remarks I may allude to the production of vulcanised rubber depending on the formation of additive compounds of the hydrocarbon with sulphur. In this connection I should mention the recent experiments of $\mathrm{Mr}$. Bamber in Ceylon, which appear to show that vulcanisation may be accomplished by acting on the uncoagulated latex with chloride of sulphur. If this proves to be practicable, it may mean the transference to the tropics of the subsidiary industry of valcanisation, which is at present carried on in Europe.

Owing to the importance and interest which attach to the chemistry of rubber, it is to form an important feature in the work of this Section at the York Meeting. Papers will be contributed by some of the best known workers in this field, by Prof. Tilden, and by Prof. Harries, of Kiel, who will give an account of his recent work; whilst Mr. Pickles, of the Imperial Institute, will present a report summarising the whole of our chemical knowledge of the subject.

The chemical investigation of raw materials often raises, unexpectedly, problems of great scientific interest. The examination at the Imperial Institute of the seeds of the Para rubber tree (Hevea brasiliensis) has shown that they contain what proves to be a valuable drying oil, and in the course of the investigation it was ascertained that there is also present in the seeds an enzyme closely allied to, if not identical with, lipase, which is capable of splitting the oil by hydrolysis into glycerin and the free fatty acid. Subsequently, during the examination of other oil seeds similar enzymes have been detected, and it would appear probable that most oil seeds may prove to contain an enzyme capable of decomposing the fatty constituent.

Another subject of great chemical interest and botanical importance which has come into prominence in connection with the Indian and Colonial work of the Imperial Institute is to be included in a joint discussion which has been arranged with the Section of Botany. I refer to the production of prussic acid by plants, which, as I have elsewhere suggested, it is convenient to refer to as cyanogenesis. In this discussion we shall have the advantage of the cooperation of Prof. Van Romburgh and Dr. Greshoff, whose work with Dr. Treub of Java on this subject is known to chemists and botanists alike. The history of the erigin of the several investigations in which Dr. Henry has been associated with me is not without interest in connection with the principal subject of this Address. During the first British expedition to the Sudan against the Mahdi a number of transport animals were poisoned through eating a small vetch which springs up in the Nile Valley during the fall of the river. The plant (Lotus arabicus) is well known to the Arabs, by whom it is cut when fully grown, and used as fodder for animals.

The results of the investigation of this matter which were communicated to the Royal Society proved that the young plant generated prussic acid when crushed with water. It was found to contain a new glucoside, lotusin, together with an enzyme capable of decomposing it into prussic acid, dextrose, and a yellow colouring matter, lotoflavin.

The glucoside is of special chemical interest, as being the only one known which contains the cyanogen group attached in the molecule to the sugar residue. Further investigation has shown that other fodder plants which are occasionally poisonous owe this character to the existence of other cyanogenetic glucosides. In a series of papers communicated to the Royal Society, Dr. Henry and I have described the properties and constitution of dhurrin No. 1919 , vo[. 74] from Sorghum vulgare, and of phaseolunatin, which we have shown to be responsible for the production of prussic acid by Phaseolus lunatus (Lima beans), Manihot utilissima (cassava or tapioca), and by linseed (the flax plant). Phaseolunatin is remarkable in furnishing acetone as one of its products of hydrolysis. The investigation, besides fulfilling the primary purpose for which it was carried out, has raised a host of problems;--as to the constitution of glucosides, the nature of the enzymes which accompany them in the plants, and also in relation to the fundamental question of plant metabolism.

Another subject of Imperial as well as National importance is to be the subject of a joint discussion with the Section of Physiology. I refer to the problem of diet. As chemists we are interested in this subject chiefly from the point of view of the composition of foods, and of the molecular structure which is associated with dietetic value. The first attempt to deal with the matter from the scientific side was made by a great chemist, Liebig. We are now in a position to investigate the problem more minutely, and the work of American physiologists has already led to important results. We have still to learn how materials such as rice and potatoes, which are nearly free from proteids, continue nevertheless to serve as the main diet of large numbers of people. It would seem that the best plan of operations will be for physiologists to settle by the accurate methods now available the precise value of typical foodstuffs, and for the chemist to deal with these in relation to their composition, and finally with reference to the constitution of their constituents. The time has come when an advance must be made from the chemical side in the analytical methods employed for gauging the value of food materials.

I feel that I have said much, but that I have left still more unsaid on many topics. I must leave almost untouched the entire subject of mineral chemistry, which is not only important in connection with the determination of the resources of India and the Colonies, but is also a subject somewhat neglected on its chemical side, which has been recently brought into prominence through the discovery of radio-activity.

The new radio-active mineral thorianite, from Ceylon, of which Mr. Blake and I have given an account to the Royal Society, brings me at once to a subject which raises the most fundamental of chemical questions, the nature of the elements and of the atom. The recent discussions of this subject have become so purely speculative that, whilst chemistry is bound to follow the lead of physics in this matter, chemists are inclined to consider that more well-ascertained facts are needed for any further discussion to be profitable from the chemical side.

In this Address I have ventured to urge the fuller recognition by Government of the scientific method as a powerful instrument in promoting the commercial development of the Colonies, and I have drawn attention to the important part the science of chemistry can play in the Imperial work of developing the resources of our Possessions.

No apology is needed in this place for directing attention to a subject which involves a most important practical application of our science, since one of the principal functions of the British Association is to bring science into close touch with the problems of our national life, and to interest the general public in the application of science to their solution.

I have, however, also shown that many problems of the highest scientific interest arise in connection with the investigation of these economic problems.

\section{NOTES.}

A Departmental committee has been appointed by the Home Secretary to inquire and report what diseases and injuries, other than injuries by accident, are due to industrial occupations, are distinguishable as such, and can properly be added to the diseases enumerated in the third schedule of the Workmen's Compensation Bill, rgo6, so as to entitle to compensation persons who may be affected 